\title{
Clinical Characteristics of Headache in Egyptian Patients with Idiopathic Epilepsy
}

\author{
Mohamed A. Sayed, Hazem K. Ibrahim, Alaaeldin Sedky Bekhit*, Mohamed N. Thabit, \\ Mostafa Abdelmomen
}

Department of Neurology, Sohag University Hospital, Sohag University, Sohag, Egypt

Email: *alaaeldin_sedky@yahoo.com

How to cite this paper: Sayed, M.A., Ibrahim, H.K., Bekhit, A.S., Thabit, M.N. and Abdelmomen, M. (2019) Clinical Characteristics of Headache in Egyptian Patients with Idiopathic Epilepsy. Journal of Behavioral and Brain Science, 9, 144-153. https://doi.org/10.4236/jbbs.2019.93012

Received: February 17, 2019

Accepted: March 22, 2019

Published: March 25, 2019

Copyright ( 2019 by author(s) and Scientific Research Publishing Inc. This work is licensed under the Creative Commons Attribution International License (CC BY 4.0).

http://creativecommons.org/licenses/by/4.0/

(c) (i) Open Access

\begin{abstract}
Purpose: Headache and epilepsy are common neurological disorders and their relationship is still incompletely known. The purpose of our work was to estimate the most common types of primary headache syndromes and its relation to seizure timing in epileptic patients in Upper Egypt. Patients \& Methods: In a cross-sectional study, we evaluated headaches in 100 consecutive patients with idiopathic epilepsy attending the neurology outpatient clinic and the epilepsy clinic at Sohag university hospital by complete medical history, physical and neurologic examination EEG and CT brain. Results: Of our study population, $78 \%$ of patients with epilepsy reported headaches. Migraine occurred in $70.6 \%$ of patients with headache followed by tension-type headache in $25.58 \%$ of patients and other types of headaches occurred in $2.56 \%$ of patients. There were 8 patients $(10.1 \%)$ had a pre-ictal headache, 52 patients (66.5\%) had a postictal headache and 39 patients (50\%) had an interictal headache. In our study, we found that the occurrence of headache being linked to the female sex, lower mean age, lower mean age at the onset of epilepsy, focal epilepsy, longer duration of epilepsy, high frequency of seizures and the use of polytherapy of antiepileptics. Conclusion: Headache especially migraine is an important comorbidity of epilepsy and should receive more attention especially in female patients, patients with younger age, lower mean age at epilepsy onset, longer duration of the disease, patients on polytherapy, patients with higher frequency of seizures and patients with focal epilepsy.
\end{abstract}

\section{Keywords}

Epilepsy, Headache, Migraine, Preictal Headache, Interictal Headache, Postictal Headache

\section{Introduction}

More than 70 million people of variable ages, races, and social classes, especially 
in low and middle-income countries suffer from epilepsy worldwide [1]. It was reported that the lifetime incidence of epilepsy is ranging from 1 to 26 with a peak age ranges from 30 to 50 years. The incidence of epilepsy is higher in developing compared to developed countries [2]. In Upper Egypt, the active prevalence rate ranges from 2.12 to $9.3 / 1000$ with much higher prevalence in infancy and early childhood (62.5 and 37.04/1000, respectively) while the incidence rate ranges from 123 to $150 / 100,000$ [3] [4].

Both epilepsy and headache are very common neurological disorders with episodic attacks. Patients with epilepsy may suffer from disabling headaches as one of the most common comorbidities that may add more burdens to those patients. A headache is often underdiagnosed because both physicians and patients are often paying more attention to epilepsy rather than a headache [5] [6] [7].

We aimed to estimate the most common types of primary headache syndromes and its relation to seizure timing in epileptic patients in Upper Egypt.

\section{Materials and Methods}

Across-sectional study was conducted at Sohag university hospital, Egypt. The study participants were recruited from the neurology outpatient and the epilepsy clinics of Sohag university hospital in the period from September 2016 till January 2018. The study included 100 consecutive patients with idiopathic epilepsy with disease duration of more than one year. Idiopathic epilepsy is defined as epilepsy in absence of significant past history of etiologic cause, abnormal neurological examination and/or structural brain abnormalities detected by brain imaging (CT or MRI). Patients with mental retardation, learning disabilities, behavioral disorders or other evident abnormalities that could compromise the ability to respond to the questionnaires and patients with secondary (symptomatic) epilepsy were excluded from the study by performing mini-mental state and CT brain. Informed consent was given by all patients and the study was approved by the Ethical Committee of Sohag Faculty of Medicine, Sohag University, Egypt.

Complete medical history, physical and neurologic examination were done for all patients. Electroencephalography in resting awake condition with eyes closed was done for all patients. The EEG data were acquired by a computer-based system (Nihon Kohden Neurofax, SN: 00429). Brain imaging (CT or MRI) and other laboratory investigations including complete blood count, renal functions, liver functions, random blood glucose, and serum electrolytes were done to exclude patients with symptomatic causes of epilepsy.

\subsection{Assessment of Epilepsy}

Direct interview with patients with epilepsy was done and the type of epilepsy was determined according to the criteria of the International League Against Epilepsy 2010 , the seizure frequency divided into four grades $(<1 /$ year; $\geq 1$ /year to $<1 /$ month; $\geq 1 /$ month to $<1 /$ week and $\geq 1$ /week) [8] the used medications, the predisposing factors, positive family history of headache and epilepsy, history of 
febrile convulsions and the use of analgesic and its type were taken for each of the study participants.

\subsection{Assessment of Headache}

The type of headache was determined according to the International-HeadacheClassification-III-ICHD-III-2013-Beta. According to the temporal relationship with seizures 1) a Peri-ictal headache which is further divided into a pre-ictal headache, ictal and post-ictal headache. A pre-ictal headache was defined as a headache appearing within 24 hours before the seizure. An ictal headache was present exclusively during the seizure. A post-ictal headache was defined as a headache which develops within 3 hours following a partial or generalized seizure and resolves within 72 hours after the end of the seizure. 2) An inter-ictal headache includes all headaches that manifested within a time period of the epileptic disease and whose attacks were not temporally related to an epileptic seizure (within more than 72 hours of the last seizure).

\subsection{Statistical Analysis}

Data were analyzed using STATA intercooled version 12.1. Quantitative data were represented as mean $\pm \mathrm{SD}$ for normally distributed data, and median (range) for abnormally distributed data. Student t-test or Mann-Whitney test were used for data analysis according to the normality of the distribution of the data. Qualitative data were presented as number and percentage and compared using either Chi square or fisher exact tests. $\mathrm{P}$ value was considered significant if it was less than 0.05 .

\section{Results}

One hundred patients with idiopathic epilepsy (mean age $=24.7 \pm 8.20$ years) participated in the study, 59\% percent of the patients were females and $41 \%$ were males.

\subsection{Epilepsy Related Data}

Seventy-four percent of the patients suffer focal seizures, $25 \%$ suffer generalized seizures, and one patient (1\%) suffers unclassified seizures depending on the clinical history. The mean age at the onset of epilepsy is $16.26 \pm 8.88$ years. The mean duration of epilepsy is $8.39 \pm 5.33$ years. Three patients (3\%) do not take antiepileptic medications, fifty patients (50\%) take one antiepileptic drug (monotherapy) for treatment and forty-seven patients (47\%) were taking more than one antiepileptic drug (polytherapy). Nineteen patients (19\%) had a seizure frequency of $<1$ seizure per year, 17 patients (17\%) had a seizure frequency of $\geq 1$ /year to $<1 /$ month, 44 patients (44\%) had a seizure frequency of $\geq 1$ /month to $<1 /$ week and 20 patients $(20 \%)$ had a seizure frequency of $\geq 1$ seizure per week. Eleven patients (11\%) had a previous history of febrile convulsions. Eighteen patients (18\%) had a positive family history of epilepsy. Twelve patients (12\%) had a pos- 
itive family history of a chronic headache including migraine and its subtypes. Inter-ictal EEG was normal in 41 patients (41\%), showed focal epileptiform discharges in 51patients (51\%) while 8 patients (8\%) have generalized epileptiform discharges. Of patients with focal epileptiform discharges, left hemispheric discharges were present in 27 patients (51\%) and right hemispheric discharges in 24 patients (49\%), temporal discharges in 23 patients (45\%), frontal discharges in 23 patients (45\%) and occipital discharges in 5 patients (10\%).

\subsection{Headache Related Data}

Seventy-eight patients with epilepsy (78\%) were suffering from headache. Migraine was diagnosed in 56 patients $(70.6 \%$; 6 patients suffered a migraine with aura, 45 patients suffered a migraine without aura, and 5 patients suffered probable migraine). The second most prevalent headache was tension type headache that occurred in 20 patients (25.58\%) including 18 patients (23.08\%) with tension type headache and 2 patients $(2.56 \%)$ with probable tension headache. Only 2 patients (2.56\%) had other types of headaches; one patient had episodic cluster headache and the other had a probable cluster headache. The degree of severity of headache in patients with headache was as the following: Mild degree in 10 patients $(12.82 \%)$, moderate degree in 50 patients $(64.10 \%)$ and severe degree in 18 patients (23.08\%) [9].

\subsection{Relation of Headache to Seizure Timing}

There were 8 patients $(10.1 \%)$ had a pre-ictal headache that evolved into seizures including 4 patients had only pre-ictal headache, 2 patients had both pre-ictal and post-ictal headaches and 2 patients had pre-ictal, post-ictal and inter-ictal headaches. There were 52 patients $(66.5 \%)$ had a post-ictal headache who reported a headache after seizure including 33 patients $(42.31 \%)$ had only post-ictal headache, 15 patients $(19.23 \%)$ had a post-ictal and inter-ictal headache, 2 patients $(2.56 \%)$ had post-ictal and pre-ictal and 2 patients $(2.56 \%)$ had three types of pre-ictal, post-ictal and inter-ictal headaches. There were 39 patients (50\%) had inter ictal headache who reported a headache in between seizures and not related to them including 22 patients (28.21\%) had only inter-ictal headache, 15 patients (19.23\%) had post-ictal and inter-ictal headache and 2 patients (2.56\%) had post-ictal, inter-ictal and pre-ictal headache (Table 1).

\subsection{Comparison between Headache Group and Non-Headache Group}

Population characteristics and intergroup differences analysis results regarding headache existence are shown in (Table 2). There were statistically significant differences in age, gender, age at onset of epilepsy, epilepsy duration, epilepsy type, the frequency of seizures and EEG finding between both groups. But there were no statistically significant differences in family history of a headache and epilepsy and history of febrile convulsions between both groups. 
Table 1. The timing of headache in relation to the epileptic seizures.

\begin{tabular}{ccccccc}
\hline & \multicolumn{5}{c}{ Timing of headache } \\
\cline { 2 - 7 } Patients & \multicolumn{5}{c}{ Peri-ictal } & \multicolumn{4}{c}{ Inter-ictal } \\
\cline { 2 - 7 } & Pre-ictal & Pre \& post-ictal & Post-ictal & Inter-ictal & Post \& inter-ictal & $\begin{array}{c}\text { Pre, Post \& } \\
\text { inter-ictal }\end{array}$ \\
\hline Number & 4 & 2 & 33 & 22 & 15 & 2 \\
Percentage & $5.13 \%$ & $2.56 \%$ & $42.31 \%$ & $28.21 \%$ & $19.23 \%$ & $2.56 \%$ \\
\hline
\end{tabular}

Table 2. Relationship between presence of headache and epilepsy characteristics.

\begin{tabular}{|c|c|c|c|}
\hline Variables & $\begin{array}{c}\text { No headache } \\
\quad N=22\end{array}$ & $\begin{array}{c}\text { Headache } \\
\mathrm{N}=78\end{array}$ & $P$ value \\
\hline \multicolumn{4}{|l|}{ Gender } \\
\hline Females & $2(9.09 \%)$ & $57(73.08 \%)$ & \multirow{2}{*}{$<0.0001$} \\
\hline Males & $20(90.91 \%)$ & $21(26.92 \%)$ & \\
\hline \multicolumn{4}{|l|}{ Age/years } \\
\hline Mean \pm SD & $28.05 \pm 7.26$ & $23.76 \pm 8.25$ & \multirow{2}{*}{0.02} \\
\hline Median (range) & $29.5(15-40)$ & $21(12-50)$ & \\
\hline \multicolumn{4}{|l|}{ Epilepsy type } \\
\hline Focal & $12(54.55 \%)$ & $62(79.49 \%)$ & \multirow{3}{*}{0.02} \\
\hline Generalized & $9(40.91 \%)$ & $16(20.51 \%)$ & \\
\hline Unclassified & $1(4.55 \%)$ & 0 & \\
\hline \multicolumn{4}{|c|}{ Age of onset of epilepsy } \\
\hline Mean \pm SD & $24.64 \pm 6.94$ & $13.90 \pm 7.92$ & $<0.0001$ \\
\hline \multicolumn{4}{|l|}{ Epilepsy duration } \\
\hline Mean \pm SD & $3.41 \pm 2.41$ & $9.79 \pm 5.09$ & $<0.0001$ \\
\hline \multicolumn{4}{|l|}{ Type of therapy } \\
\hline No therapy & 0 & $3(3.85 \%)$ & \multirow{3}{*}{$<0.0001$} \\
\hline Monotherapy & $20(90.91 \%)$ & $30(38.46 \%)$ & \\
\hline Poly therapy & $2(9.09 \%)$ & $45(57.69 \%)$ & \\
\hline \multicolumn{4}{|l|}{ Frequency of epilepsy } \\
\hline$<1 /$ year & $9(40.91 \%)$ & $10(12.82 \%)$ & \multirow{4}{*}{$<0.0001$} \\
\hline$\geq 1 /$ year, $<1 /$ month & $8(36.36 \%)$ & $9(11.54 \%)$ & \\
\hline$\geq 1 /$ month, $<1 /$ week & $3(13.64 \%)$ & $41(52.56 \%)$ & \\
\hline$\geq 1 /$ week & $2(9.09 \%)$ & $18(23.08 \%)$ & \\
\hline \multicolumn{4}{|c|}{ History of febrile convulsions } \\
\hline No & $21(95.45 \%)$ & $68(87.18 \%)$ & \multirow{2}{*}{0.45} \\
\hline Yes & $1(4.55 \%)$ & $10(12.82 \%)$ & \\
\hline \multicolumn{4}{|l|}{ EEG finding } \\
\hline Normal & $18(81.82 \%)$ & $23(29.49 \%)$ & \multirow{3}{*}{$<0.0001$} \\
\hline Generalized & $1(4.55 \%)$ & $7(8.97 \%)$ & \\
\hline Focal & $3(13.64 \%)$ & $48(61.54 \%)$ & \\
\hline \multicolumn{4}{|c|}{ Family history of epilepsy } \\
\hline No & $18(81.82 \%)$ & $64(82.05 \%)$ & \multirow{2}{*}{1.00} \\
\hline Yes & $4(18.18 \%)$ & $14(17.95 \%)$ & \\
\hline \multicolumn{4}{|c|}{ Family history of headache } \\
\hline No & $22(100 \%)$ & $66(84.62 \%)$ & \multirow{2}{*}{0.06} \\
\hline Yes & 0 & $12(15.38 \%)$ & \\
\hline
\end{tabular}




\subsection{Antiepileptic and Analgesic Drugs}

Patients suffering from headaches were more commonly polytherapy as regard antiepileptic drugs (57.69\%) compared to those without headaches $(9.09 \%)(\mathrm{P}=$ $<0.0001)$. Among patients with a headache only 34 patients $(43.59 \%)$ use analgesic for the treatment of a headache and 44 patients (56.41\%) didn't use any medications for treatment. The majority of patients 26 patients $(76.47 \%)$ used analgesics without seeking medical advice and only 8 patients $(23.53 \%)$ used analgesics prescribed by a doctor after seeking medical advice.

\section{Discussion}

Headache is very common among patients with epilepsy. However, its frequency is very variable among various studies. Some studies reported similar frequency and other studies reported lower frequency compared to our study. Mameniskiene et al. reported that $82.2 \%$ of patients with epilepsy suffered from headache in his study population [10]. However, lower frequencies were reported in other studies; $22 \%$ by Kwan et al., 2008 or 34\% by Kanemura et al., 2013 [11] [12]. These differences can be explained by variations in the characteristics of the recruited patients with epilepsy including age; newly diagnosed patients; patients with less refractory epilepsy; patients referred to tertiary centers; study design, and/or diagnostic criteria [13].

As regard the type of headache, we found that migraine was the most frequent type of headache in patients with epilepsy including (57.69\%) migraine without aura $(6.69 \%)$, a migraine with aura and $(6.41 \%)$ probable migraine and the second most frequent type is tension-type headache (25.64\%). Similar findings were found in several studies [3] [4] [12] [14] [15] [16] and those results suggest the relationship and common pathophysiological mechanisms of both epilepsy and migraine. Seo et al., 2016 recorded that the most common headache type identified was tension type headache and the high prevalence of tension-type headaches may be explained by frequent use of valproate and topiramate in the study sample as these drugs are used and approved in the prophylaxis of migraine and could prevent its occurrence [13]. As regard the time of headache we found that post-ictal headache is the commonest type of headache followed by the inter-ictal and less commonly the pre-ictal type and this result is in agreement with many studies [6] [7] [14] [15] [17] [18]. This could be explained by the triggering effect of epileptic seizure on headache occurrence and the greater ease by which cortical spreading depression can be reached in the post-seizure period. On the other hand, some studies found that inter-ictal headache is the most common [3] [15].

We found that younger patients with epilepsy, especially females, are more liable to develop headache compared to older ones. This finding is similar to other studies [7] [8] [11] [19] [20] [21] [22] and can be explained by the fact that headache in general usually occurs in younger age groups and more common in 
females [18] [23]. In contrast to our result, few studies reported no statistically significant differences in age and sex between patients with headaches compared to those without [5] [10].

Patients with epilepsy associated with headaches have a significantly lower age of onset and longer duration of epilepsy compared to those without headache. Many studies showed similar results to our study [2] [15] [19] [24] which may be explained by the fact that a headache especially migraine is more common in younger ages. Moreover, headache is more common with intractable epilepsy with a long duration. In contrast to our result, Forderreuther et al., 2002 found no statistically significant differences in the age of onset or the duration of epilepsy between headache and non-headache groups [5].

Similar to the results of other studies [5] [8] [12] [14] [16] [19] [22] [24], patients with epilepsy in whom the seizure frequency is high, and those receiving polytherapy suffers significantly more headaches compared to those with lower seizure frequency and monotherapy for epilepsy treatment. These results suggest that intractable seizures which are more frequent and need polytherapy for control act as a trigger for cortical spreading depression and frequent migraine headaches. Moreover, repeated seizures and difficulty of control of the mare usually associated with more psychological stress which may increase the incidence of tension-type headache.

In our study, we found that there was no significant association between headache and family history of headache or epilepsy and the same findings were reported by some studies [12] [13] [21]. On the other hand, fewer studies reported a significant association between the occurrence of headache and family history of headache and epilepsy [20]. Also, we found that there was no significant association between headache and previous history of febrile convulsions and this was the same findings by Seo et al., 2016.

We found a significant association between headache and the focal onset seizures and this was reported also by many studies [12] [20] [25] [26]. Neuronal discharges in partial seizures may trigger vascular changes and that partial seizures, which spread to brainstem and hypothalamus, may induce headaches [12] [27] [28]. Other studies found no significant association between the occurrence of headache and type of epilepsy [5] [21]. Our results also showed that abnormal EEG, especially those with focal discharges, is more common in patients with a headache compared to those without. Similar results were also reported in some studies [20] [25].

Our study has some limitations. First, our interview was dependent on patients' memory of headaches. Second, the findings reported here were based on a sample size of 100 participants. Accordingly, future studies should focus on a larger pool. Thirdly, the use of routine EEG recording which gave us limited information about focality of epilepsy so in the next studies we will need other investigations to accurately assess seizure focality and correlates these findings with seizure semiology. 


\section{Conclusion}

In conclusion, our study showed that patients with epilepsy frequently experience headaches. Migraine is the most prevalent type of headache in patients with epilepsy. Post-ictal headache occurs more frequently compared to inter-ictal headache. Pre-ictal and ictal headaches were rare. In our study we found that the occurrence of headaches was more in the female sex, lower mean age of the patient and lower mean age at the onset of epilepsy. Patients with focal epilepsy, longer duration of epilepsy, higher frequency of seizures and those in whom polytherapy is used suffer more headaches. Patient with abnormal EEG, especially those with focal abnormalities, were more commonly suffering from headache. The comorbidity between headache and epilepsy is extremely important, as headaches often receive less attention than the more dramatic symptoms of seizures. In epilepsy, questions concerning headache should be an integral part of the history as comorbidity may influence the antiepileptic drug choice, and the migraine may need specific treatment.

\section{Conflicts of Interest}

The authors declare no conflicts of interest regarding the publication of this paper.

\section{References}

[1] Ngugi, A.K., Kariuki, S.M., Bottomley, C., Kleinschmidt, I., Sander, J.W. and Newton, C.R. (2011) Incidence of Epilepsy: A Systematic Review and Meta-Analysis. Neurology, 77, 1005-1012. https://doi.org/10.1212/WNL.0b013e31822cfc90

[2] Petitmengin, C. (2006) Describing One's Subjective Experience in the Second Person: An Interview Method for the Science of Consciousness. Phenomenology and the Cognitive Sciences, 5, 229-269. https://doi.org/10.1007/s11097-006-9022-2

[3] Fawi, G., Khedr, E.M., El-Fetoh, N.A., Thabit, M.N., Abbass, M.A. and Zaki, A.F. (2015) Community-Based Epidemiological Study of Epilepsy in the Qena Governorate in Upper Egypt, a Door-to-Door Survey. Epilepsy Research, 113, 68-75. https://doi.org/10.1016/j.eplepsyres.2015.03.010

[4] Khedr, E.M., Shawky, O.A., Ahmed, M.A., Elfetoh, N.A., Al Attar, G., Ali, A.M., Kandil, M.R. and Farweez, H. (2013) A Community Based Epidemiological Study of Epilepsy in Assiut Governorate/Egypt. Epilepsy Research, 103, 294-302. https://doi.org/10.1016/j.eplepsyres.2012.08.006

[5] Forderreuther, S., Henkel, A., Noachtar, S. and Straube, A. (2002) Headache Associated with Epileptic Seizures: Epidemiology and Clinical Characteristics. Headache, 42, 649-655. https://doi.org/10.1046/j.1526-4610.2002.02154.x

[6] Kingston, W.S. and Schwedt, T.J. (2017) The Relationship between Headaches with Epileptic and Non-Epileptic Seizures: A Narrative Review. Current Pain and Headache Reports, 21, 17. https://doi.org/10.1007/s11916-017-0617-9

[7] Syvertsen, M., Helde, G., Stovner, L.J. and Brodtkorb, E. (2007) Headaches Add to the Burden of Epilepsy. The Journal of Headache and Pain, 8, 224-230. https://doi.org/10.1007/s10194-007-0398-3

[8] Cilliler, A.E., Guven, H. and Comoglu, S.S. (2017) Epilepsy and Headaches: Further Evidence of a Link. Epilepsy \& Behavior, 70, 161-165. https://doi.org/10.1016/j.yebeh.2017.03.009 
[9] Boonstra, A.M., Schiphorst Preuper, H.R., Balk, G.A. and Stewart, R.E. (2014) Cut-Off Points for Mild, Moderate, and Severe Pain on the Visual Analogue Scale for Pain in Patients with Chronic Musculoskeletal Pain. Pain, 155, 2545-2550. https://doi.org/10.1016/j.pain.2014.09.014

[10] Mameniskiene, R., Karmonaite, I. and Zagorskis, R. (2016) The Burden of Headache in People with Epilepsy. Seizure, 41, 120-126. https://doi.org/10.1016/j.seizure.2016.07.018

[11] Kwan, P., Man, C.B., Leung, H., Yu, E. and Wong, K.S. (2008) Headache in Patients with Epilepsy: A Prospective Incidence Study. Epilepsia, 49, 1099-1102. https://doi.org/10.1111/j.1528-1167.2008.01574.x

[12] Kanemura, H., Sano, F., Ishii, S., Ohyama, T., Sugita, K. and Aihara, M. (2013) Characteristics of Headache in Children with Epilepsy. Seizure, 22, 647-650. https://doi.org/10.1016/j.seizure.2013.04.022

[13] Seo, J.H., Joo, E.Y., Seo, D.W. and Hong, S.B. (2016) Correlation between Headaches and Affective Symptoms in Patients with Epilepsy. Epilepsy \& Behavior, 60, 204-208. https://doi.org/10.1016/j.yebeh.2016.03.028

[14] Ekstein, D. and Schachter, S.C. (2010) Postictal Headache. Epilepsy \& Behavior, 19, 151-155. https://doi.org/10.1016/j.yebeh.2010.06.023

[15] Group, H.S. (2009) Multi-Center Study on Migraine and Seizure-Related Headache in Patients with Epilepsy. Yonsei Medical Journal, 51, 219-224.

[16] Mainieri, G., Cevoli, S., Giannini, G., Zummo, L., Leta, C., Broli, M., Ferri, L., Santucci, M., Posar, A., Avoni, P., Cortelli, P., Tinuper, P. and Bisulli, F. (2015) Headache in Epilepsy: Prevalence and Clinical Features. The Journal of Headache and Pain, 16, 72. https://doi.org/10.1186/s10194-015-0556-y

[17] Kasteleijn-Nolst Trenite, D.G., Verrotti, A., Di Fonzo, A., Cantonetti, L., Bruschi, R., Chiarelli, F., Villa, M.P. and Parisi, P. (2010) Headache, Epilepsy and Photosensitivity: How Are They Connected? The Journal of Headache and Pain, 11, 469-476. https://doi.org/10.1007/s10194-010-0229-9

[18] Stovner, L., Hagen, K., Jensen, R., Katsarava, Z., Lipton, R., Scher, A., Steiner, T. and Zwart, J.A. (2007) The Global Burden of Headache: A Documentation of Headache Prevalence and Disability Worldwide. Cephalalgia, 27, 193-210. https://doi.org/10.1111/j.1468-2982.2007.01288.x

[19] Gameleira, F.T., Ataide, L. and Raposo, M.C. (2013) Relations between EPILEPTIC seizures and Headaches. Seizure, 22, 622-626. https://doi.org/10.1016/j.seizure.2013.04.016

[20] Toldo, I., Perissinotto, E., Menegazzo, F., Boniver, C., Sartori, S., Salviati, L., Clementi, M., Montagna, P. and Battistella, P.A. (2010) Comorbidity between Headache and Epilepsy in a Pediatric Headache Center. The Journal of Headache and Pain, 11, 235-240. https://doi.org/10.1007/s10194-010-0191-6

[21] Wang, X.Q., Lang, S.Y., He, M.W., Zhang, X., Zhu, F., Dai, W., Shi, X.B., Wan, M., Ma, Y.F., Chen, Y.N. and Yu, S.Y. (2014) High Prevalence of Headaches in Patients with Epilepsy. The Journal of Headache and Pain, 15, 70. https://doi.org/10.1186/1129-2377-15-70

[22] Wang, X.Q., Lang, S.Y., Zhang, X., Zhu, F., Wan, M., Shi, X.B., Ma, Y.F., He, M.W. and Yu, S.Y. (2014) Comorbidity between Headache and Epilepsy in a Chinese Epileptic Center. Epilepsy Research, 108, 535-541. https://doi.org/10.1016/j.eplepsyres.2013.12.013

[23] Rasmussen, B.K., Jensen, R., Schroll, M. and Olesen, J. (1991) Epidemiology of Headache in a General Population-A Prevalence Study. Journal of Clinical Epidemiology, 44, 1147-1157. https://doi.org/10.1016/0895-4356(91)90147-2 
[24] Velioglu, S.K., Boz, C. and Ozmenoglu, M. (2005) The Impact of Migraine on Epilepsy: A Prospective Prognosis Study. Cephalalgia, 25, 528-535.

https://doi.org/10.1111/j.1468-2982.2005.00912.x

[25] Verrotti, A., Coppola, G., Spalice, A., Di Fonzo, A., Bruschi, R., Tozzi, E., Iannetti, P., Villa, M.P. and Parisi, P. (2011) Peri-Ictal and Inter-Ictal Headache in Children and Adolescents with Idiopathic Epilepsy: A Multicenter Cross-Sectional Study. Child s Nervous System, 27, 1419-1423. https://doi.org/10.1007/s00381-011-1428-7

[26] Wirrell, E.C. and Hamiwka, L.D. (2006) Do Children with Benign Rolandic Epilepsy Have a Higher Prevalence of Migraine than Those with Other Partial Epilepsies or Nonepilepsy Controls? Epilepsia, 47, 1674-1681.

[27] Bolay, H., Reuter, U., Dunn, A.K., Huang, Z., Boas, D.A. and Moskowitz, M.A. (2002) Intrinsic Brain Activity Triggers Trigeminal Meningeal Afferents in a Migraine Model. Nature Medicine, 8, 136-142. https://doi.org/10.1038/nm0202-136

[28] Moskowitz, M.A., Bolay, H. and Dalkara, T. (2004) Deciphering Migraine Mechanisms: Clues from Familial Hemiplegic Migraine Genotypes. Annals of Neurology, 55, 276-280. https://doi.org/10.1002/ana.20035 